\title{
RESSECÇÃO VIDEOLAPAROSCÓPICA DE HEMANGIOPERICITOMA DO ESTÔMAGO
}

\section{LAPAROSCOPIC RESECTION FOR HEMANGIOPERICYTOMA OF THE STOMACH}

\author{
João Luiz M. C. Azevedo, TCBC-SP1 \\ Jean Boulez ${ }^{2}$ \\ Philippe Espalieu ${ }^{3}$
}

\section{INTRODUÇÃO}

Os hemangiopericitomas são tumores raros, derivados dos pericitos, só identificados mediante microscopia eletrônica ou por imuno-histoquímica, portanto sem características peculiares à microscopia ótica. ${ }^{1}$ São definidos pela reatividade aos imunomarcadores vimentina e CD34, produzidos pelos pericitos tumorais. ${ }^{2}$

Afirma-se que os pericitos representam células mesenquimais residuais que permanecem disponíveis para o reparo do tecido conjuntivo e dos vasos sangüíneos lesados. ${ }^{3}$ Dessa forma, o hemangiopericitoma pode ser rotulado como neoplasia mesenquimal. Apenas 29 casos de hemangiopericitomas da parede gástrica foram relatados na literatura. ${ }^{4}$

Como ocorre de uma forma geral nos tumores extramucosos de origem mesenquimal do tubo digestivo, nenhum sinal clínico ou de imagem é capaz de diagnosticar a natureza dos hemangiopericitomas gástricos no pré-operatório. Tampouco é possível prever-se a sua evolução, sendo o único sinal prognóstico a ocorrência ou não de infiltração em outros órgãos e de metástases linfonodais ou a distância. ${ }^{5}$

\section{RELATO DO CASO}

Paciente do sexo feminino, de 77 anos de idade. Na investigação para hérnia hiatal foi detectado, por endoscopia e ecoendoscopia, tumor gástrico submucoso, com diagnóstico de provável leiomioma ou schwanoma. A radiologia contrastada (Figura 1) e a tomografia computadorizada (Figura 2) confirmaram a localização da lesão no nível da pequena curvatura gástrica.

Através de laparoscopia, foi feita dissecção da pequena curvatura e ressecção tumoral junto com $2 \mathrm{~cm}$ de segmento gástrico não comprometido, mediante nove aplicações do dispositivo automático de sutura reta por grampos "Multifire Endo GIA-30". Para tanto, cinco portas laparoscópicas foram necessárias, sendo duas de $10 \mathrm{~mm}$, uma de $12 \mathrm{~mm}$ e duas de $5 \mathrm{~mm}$. A ótica de $30^{\circ}$ foi posicionada em porta de $10 \mathrm{~mm}$, situada na cicatriz umbilical. Dois centímetros à direita e abaixo do apêndice xifóide se colocou uma porta de $10 \mathrm{~mm}$ para o afastamento cranial do fígado. A $8 \mathrm{~cm}$ abaixo do rebordo costal direito, no nível da linha hemiclavicular, posicionou-se uma porta de $5 \mathrm{~mm}$ para o trabalho da mão esquerda do cirurgião. Para a sua mão direita, instalou-se uma porta de $12 \mathrm{~mm}$ na linha axilar anterior esquerda, $6 \mathrm{~cm}$ abaixo do rebordo costal, para a aplicação do Endo GIA. Uma outra porta de $5 \mathrm{~mm}$ foi postada na linha hemiclavicular esquerda, $3 \mathrm{~cm}$ abaixo da cicatriz umbilical, para tração do estômago em direção caudal e esquerda.

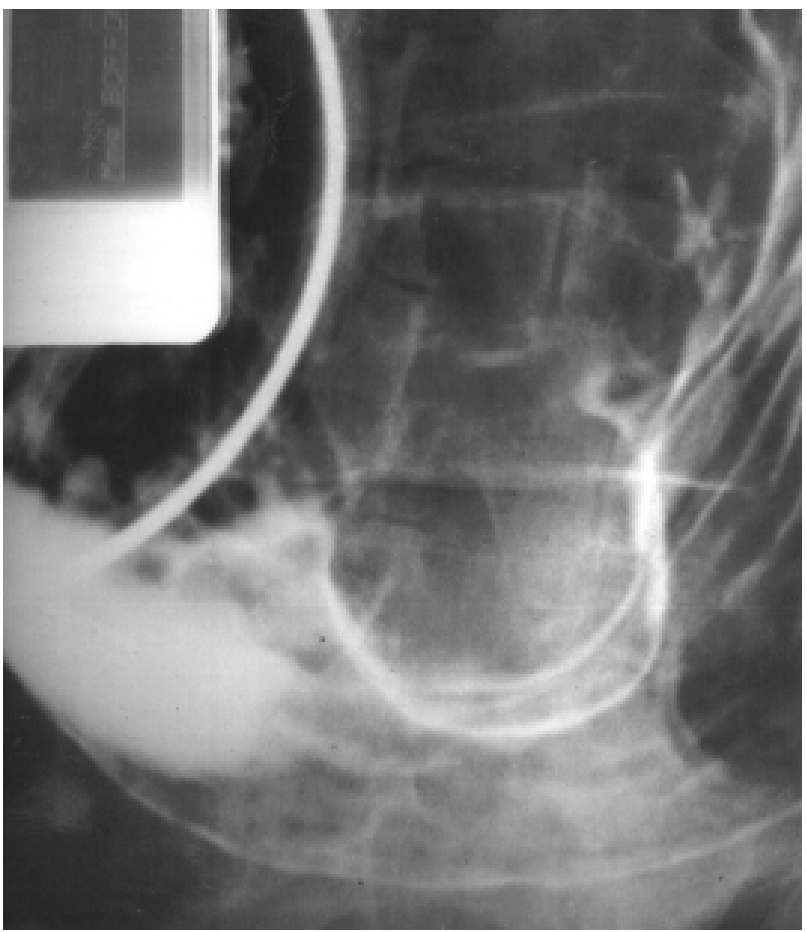

Figura 1 - Aspecto radiológico de tumor extramucoso de pequena curvatura gástrica

1. Professor Adjunto Doutor do Departamento de Cirurgia da Universidade Federal de São Paulo (UNIFESP), Escola Paulista de Medicina (EPM). Professor convidado da Universidade Claude Bernard, Lyon, França. PhD, FICS.

2. Professor Titular do Departamento de Cirurgia Geral e Digestiva da Faculdade de Medicina da Universidade Claude Bernard, Lyon, França.

3. Cirurgião do Hospital Edouard Herriot, Lyon, França

Recebido em 21/5/99

Aceito para publicação em 20/12/99

Trabalho realizado na Fédération des spécialités digestives, Pavillon D-O, E. Herriot - Lyon - França. 


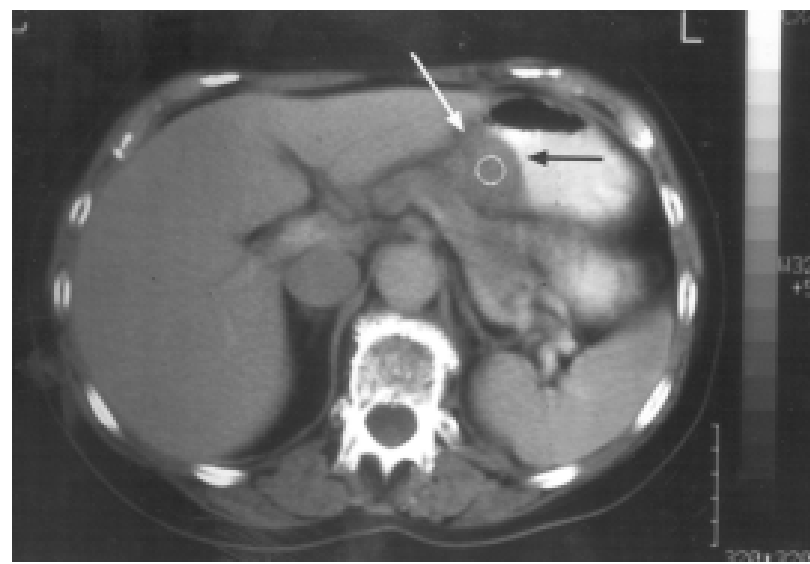

Figura 2 - Tomografia computadorizada: tumor de pequena curvatura gástrica (setas)

A técnica de ressecção incluiu a neoplasia e segmento da parede gástrica, com pelo menos $2 \mathrm{~cm}$ de tecido são em torno do tumor. A gastroscopia intra-operatória foi indispensável para a localização da base de implantação do tumor, servindo também para inspeção da linha de sutura após a ressecção.

Exame histopatológico demonstrou tumor de células fusiformes de $3 \mathrm{~cm}$ de diâmetro, com índice mitótico quase nulo. A imuno-histoquímica evidenciou positividade para vimentina e para o imunomarcador CD34, com negatividade para proteína $\mathrm{S}-100$, actina, desmina e para Ag ligada ao fator VIII. O tecido tumoral era discreta- mente reagente à queratina. A reação com o fator XIIIa mostrou elementos dendríticos em menos de 5\% da área. Estes dados indicam uma origem de célula vascular mais que uma de célula muscular lisa, razão pela qual foi diagnosticado hemangiopericitoma gástrico. Seguimento pósoperatório no total de sete anos, sem recidiva.

\section{DISCUSSÃO}

Do ponto de vista de viabilidade técnica, a ressecção segmentar do estômago nos tumores mesenquimais não oferece dificuldades especiais. Entretanto, cumpre notar que, no estômago, procedimento de simples enucleação não deve ser empreendido. A enucleação simples é adequada no esôfago, onde os tumores extramucosos são constituídos em sua maioria por leiomiomas. ${ }^{5}$ Mesmo assim, após a sua remoção impõe-se estreita vigilância, pois o único critério absoluto de que se tratava de lesão benigna é a ausência de recidiva local, de invasão regional e de metástases a distância. ${ }^{5}$

Contrariamente, a menor extensão da operação no estômago não deve ser a enucleação, mas a ressecção gástrica segmentar (exérese da lesão incluindo-se adequada margem - pelo menos $2 \mathrm{~cm}$ - de tecido não comprometido). Isso por causa da elevada freqüência de malignidade nos tumores mesenquimais de estômago (o leiomioma é muito raro nesse órgão), aliada à dificuldade de ser detectada a presença de câncer no pré-operatório. ${ }^{5}$

Tumores gástricos mesenquimais podem ser cancerosos sem entretanto apresentarem estigmas nítidos desse caráter. ${ }^{5} \mathrm{~A}$ ressecção segmentar é suficiente para a cura de grande número de pacientes, contanto que invasão de outros órgãos ou metástases linfonodais não estejam presentes. ${ }^{5}$

\begin{abstract}
In the present case (77 years-old woman), the diagnosis on an extramucosal lesion by endosonography was leiomyoma or schwanoma. Radiological exam of the upper digestive tract with barium and abdominal computed tomography confirmed the site of the lesion at the level of the lesser curvature. The operative technique followed the steps of the laparoscopic partial gastric resection (wedge resection) for gastric mesenchymal tumours, described elsewhere. The Endo-GIA stapler was introduced through the $12 \mathrm{~mm}$ port in the right upper quadrant. Proper positioning of the stapler over the lesser curvature and a satisfactory margin of tissue around the mass were attained. Nine sequential firings of the Endo-GIA 30 were needed to completely surround the mass. Histopathological diagnosis was a spindlecell tumour measuring $3 \mathrm{~cm}$ in diameter. Mitotic index was measured at almost null. The neoplastic cells were strongly reactive for vimentine and $C D 34$ and negative for the immunohistochemical markers $S$-100 protein, muscle actin, desmin and Ag linked to VIII factor. There was a slight reaction with keratin (+/+++). The XIIIA factor reaction revealed less than $5 \%$ of dendritic elements. These data favour a vascular cell origin better than smooth muscle cell origin. In conclusion it was a gastric hemangiopericytoma. Follow-up showed no recurrence at seven years.
\end{abstract}

Key Words: Gastric haemangiopericytoma; Gastric mesenchymoma; Laparoscopic surgery; Minimally invasive surgery; Stomach, surgery; Surgical techniques.

\section{REFERÊNCIAS}

1. Nappi O, Ritter JH, Pettint OG et al. Hemangiopericytoma: histopathological pattern or clinicopathological entity? Semin Diagn Pathol 1995; 12:221-232.

2. Erlandson RA, Klimstra DS, Woodruff JM. Subclassification of gastrointestinal stromal tumors based on evaluation by electron microscopy and immunohistochimestry. Ultraestruct Pathol 1996; 20:373-393

3. Pandey M, Kothari KC, Patel DD. Hemangiopericytoma: current status, diagnosis and management. Eur J Surg Oncol 1997; 23:282-285

4. Guadagni S, Gianfelice F, Pistoia MA et al. Un caso de emangiopericitoma dello stomaco. Minerva Chir 1995; 50:693-698.
5. Emory TS, Sobin LH, Lukes L, Lee DH, O'Leary TJ. Prognosis of gastrointestinal smooth-muscle (stromal) tumors: dependence on anatomic site. Am J Surg Pathol 1999; 23:82-87.

\author{
ENDEREÇO PARA CORRESPONDÊNCIA: \\ Dr. João Luiz M. C. Azevedo \\ Rua Joaquim Tavora, 550/101-A \\ 04015-011 - São Paulo-SP \\ E-mail: jozevedo.dcir@epm.br
}

